\title{
Evaluating outcomes associated with a discharge action plan employing single-dose home use of ondansetron in patients with acute gastroenteritis
}

This article was published in the following Dove Press journal:

Open Access Emergency Medicine

26 March 2012

Number of times this article has been viewed

\author{
Elizabeth Haines' \\ Robert van Amerongen ${ }^{2}$ \\ Robert Birkhahn' \\ Wendy Wen' \\ Theodore Gaeta' \\ 'Department of Emergency Medicine, \\ ${ }^{2}$ Pediatric Emergency Services, \\ New York Methodist Hospital, \\ Brooklyn, NY, USA
}

Correspondence: Elizabeth Haines Department of Emergency Medicine, 506 Sixth Street, Brooklyn,

NY I I2I5, USA

$\mathrm{Tel}+\mathrm{I} 7187805040$

Fax +I 718780 3153

Email ejh9003@nyp.org

\begin{abstract}
Acute gastroenteritis accounts for 1-2 million annual pediatric emergency department visits in the US. The current literature supports the use of antiemetics, such as ondansetron, in the emergency department, reporting improved oral rehydration, cessation of vomiting, and reduction in the need for intravenous rehydration. However, there remains concern that using these agents may "mask alternative diagnoses" and negatively impact patient care. We present a case series of 29 patients who received a pediatric emergency department discharge action plan which allowed for a dose of ondansetron to be dispensed by the clinician at the time of discharge. Patients were instructed to administer the ondansetron at home for treatment of ongoing nausea and vomiting any time after 6 hours from the time of emergency department discharge. These patients were followed up at 3-5 days following discharge to assess for outcomes. Implications of this discharge action plan and future directions are discussed.
\end{abstract}

Keywords: gastroenteritis, ondansetron, discharge action plan

\section{Introduction}

Acute gastroenteritis is a common childhood disease. In the US it accounts for 1-2 million pediatric emergency visits annually. ${ }^{1}$ Worldwide it has an annual morbidity of 1.87 million children under the age of 5 years. ${ }^{2}$ The American Academy of Pediatrics advocates the use of oral rehydration in the management of this disease process. ${ }^{3}$ Ondansetron, a selective 5-HT3 receptor antagonist primarily used for the prevention of nausea and vomiting associated with postoperative states, chemotherapy, and radiation therapy in children older than one month, has revolutionized emergency department care of children with acute gastroenteritis. We present an indepth analysis of 29 cases, demonstrating that a pediatric emergency department discharge action plan employing home use of ondansetron may be useful and safe for pediatric acute gastroenteritis.

\section{Case series}

All cases were from a single urban pediatric emergency department with an annual pediatric census of 20,405 patients. The cases presented over a 4-month period from January through April, 2011. The study had Institutional Review Board approval to enroll patients prospectively. A limited number of pediatric clinicians employed the discharge action plan. Their data were pooled and retrospectively reviewed. Patients aged 6 months to 20 years and suspected to have acute gastroenteritis based on vomiting and a minimum of one episode of diarrhea reported on review of systems were considered for enrollment into a discharge action plan by the treating clinician 
(see Table 1). The discharge action plan was then discussed at the time of discharge with patients and parents as appropriate. Patients/parents were given a set dose of ondansetron $(2 \mathrm{mg}$ for children $8-15 \mathrm{~kg}, 4 \mathrm{mg}$ for $15-30 \mathrm{~kg}, 8 \mathrm{mg}$ for $>30 \mathrm{~kg}$ ) with written instructions on route and timing of when the medication was to be given at home. The patient/parent was informed that the treating physician would conduct a follow-up phone call 3-5 days following their emergency visit. The treating clinician conducted a phone interview with the parent/patient who had been given the discharge medication and written instructions. The clinician assessed ondansetron use, additional episodes of emesis, emesis resolution (date and time), need for additional emergency department or unscheduled primary medical doctor visits, and if any alternative diagnosis was found during additional evaluation. All patients were successfully followed up by a clinician-conducted telephone call. Patient ages ranged from 15 months to 15 years, with a mean age of 5.15 years. The mode was 2 years. Twenty-four of 29 patients $(83 \%)$ received ondansetron at home, $72 \%$ had resolution of emesis in the emergency department with no further emesis, $24 \%$ had resolution of their emesis between time of discharge and 24 hours, and one patient reported emesis after 24 hours from time of discharge. Five patients (17\%) reported an unscheduled physician visit, all of whom returned to the study site emergency department. Four out of five return visits cited ongoing diarrhea as the reason for return. One of five returned to the emergency department for ongoing emesis. This single return visit resulted in an admission for rehydration. In follow-up calls and on review of the electronic medical records, there were no other diagnoses other than gastroenteritis, vomiting, and dehydration identified.

\section{Discussion}

Our experience with ondansetron suggests that incorporating the medication into a discharge action plan was well tolerated by a cohort of pediatric patients presenting with acute gastroenteritis. This is in agreement with a 2006 trial demonstrating

Table I Patients enrolled in discharge action plan case series

\begin{tabular}{|c|c|c|c|c|c|}
\hline Case & Age, years & $\begin{array}{l}\text { Resolution } \\
\text { of emesis }\end{array}$ & $\begin{array}{l}\text { Unscheduled } \\
\text { visit }\end{array}$ & $\begin{array}{l}\text { Alternative diagnosis } \\
\text { identified }\end{array}$ & $\begin{array}{l}\text { Ondansetron administered } \\
\text { at home }\end{array}$ \\
\hline 1 & 1.25 & In ED & No & No & Yes \\
\hline 2 & 3 & 20 hours & No & No & Yes \\
\hline 3 & 2 & 38 hours & Yes & No & Yes \\
\hline 4 & 5 & In ED & No & No & Yes \\
\hline 5 & 1.83 & In ED & No & No & No \\
\hline 6 & 5 & 12 hours & No & No & Yes \\
\hline 7 & 10 & In ED & No & No & Yes \\
\hline 8 & 2 & In ED & No & No & Yes \\
\hline 9 & 4 & 6 hours & No & No & Yes \\
\hline 10 & 14 & In ED & No & No & Yes \\
\hline II & 3 & In ED & No & No & Yes \\
\hline 12 & 2 & 24 hours & No & No & Yes \\
\hline 13 & 4 & In ED & No & No & Yes \\
\hline 14 & 6 & In ED & No & No & No \\
\hline 15 & 4 & In ED & No & No & Yes \\
\hline 16 & 5 & In ED & No & No & No \\
\hline 17 & 12 & 24 hours & Yes (ED) & No & Yes \\
\hline 18 & 15 & 12 hours & Yes (ED) & No & Yes \\
\hline 19 & 2 & In ED & Yes & No & Yes \\
\hline 20 & 2 & In ED & Yes & No & Yes \\
\hline 21 & 1.83 & In ED & No & No & Yes \\
\hline 22 & 2 & In ED & No & No & Yes \\
\hline 23 & 5 & In ED & No & No & No \\
\hline 24 & 13 & In ED & No & No & Yes \\
\hline 25 & 1.83 & In ED & No & No & No \\
\hline 26 & 5 & In ED & No & No & Yes \\
\hline 27 & 1.75 & In ED & No & No & Yes \\
\hline 28 & 2 & 6 hours & No & No & Yes \\
\hline 29 & 14 & In ED & No & No & Yes \\
\hline
\end{tabular}

Abbreviation: ED, emergency department. 
that the use of ondansetron during oral rehydration therapy is associated with decreased emesis, decreased mean number of episodes of emesis, no significant differences in rates of hospitalization, and a slight increase in mean episodes of diarrhea. ${ }^{4}$ Further, this study concluded that for a single dose of ondansetron in gastroenteritis, the number needed to treat was five to prevent vomiting and six to avoid the need for intravenous fluids. More recent literature focused on the rate of admission and emergency department revisits associated with emergency department ondansetron use and concluded that use of the drug reduces hospital admissions for patients with suspected gastroenteritis and vomiting.

Ondansetron use is also associated with an increase in return visits to the pediatric emergency department when compared with similar patients who did not receive ondansetron. ${ }^{5}$ This 2010 study follows the return visits and alternative diagnoses, citing the following as the top six most common alternative diagnoses found in patients returning to the emergency department who were presumed to have gastroenteritis on initial visit: appendicitis, intussusception, bacteremia, pyelonephritis, small bowel obstruction, and intracranial tumor. A common concern among emergency department clinicians is differentiating gastroenteritis from other causes of vomiting and diarrhea in children. Often diarrhea is a reassuring symptom that helps differentiate acute gastroenteritis from other diagnoses that involve emesis, such as appendicitis, diabetic ketoacidosis, gastrointestinal obstruction, pyloric stenosis, pancreatitis, hepatitis, and elevated intracranial pressure. Because of this concern, many clinicians will use ondansetron in the emergency department but hesitate to prescribe or advocate its use at home by patients for fear of masking an alternative diagnosis. This precaution has limited it use, despite the limited evidence that the drug, in fact, masks alternative diagnoses.

Our 29 cases suggest that there may be increased compliance and use of home ondansetron when the medication is provided in the emergency department as a component of a discharge action plan as opposed to when a prescription for ondansetron is given at the time of discharge. A previous large retrospective study looking at children with acute gastroenteritis showed that $9 \%$ of patients had a prescription filled for an antiemetic. In addition, only $5 \%$ of patients under the age of 2 years had a prescription filled. ${ }^{9}$ In our study, parents gave the ondansetron in more than $80 \%$ of cases. Although $72 \%$ had their last episode of emesis in the emergency department, over $80 \%$ took the medication at home (either as a prophylactic measure or in response to nausea). This suggests that having the medication given to them at the time of discharge decreased barriers to compliance and use of this medication at home.

In examining the safety of home use of ondansetron in the setting of suspected acute gastroenteritis, the case results indicate that the medication does not mask or cover alternative diagnoses. The side effect and reason cited for the majority $(4 / 5)$ of return visits was diarrhea. This is a known side effect with this medication and aligns with other studies that have demonstrated an increase in post-discharge diarrhea in patients who have received ondansetron in the emergency department. ${ }^{10}$ Although it could be part of the natural disease course of gastroenteritis to have more diarrhea in the later phase of the illness, a 2002 randomized, prospective, doubleblind clinical trial of 20,000 patients concluded that the group receiving ondansetron had more episodes of diarrhea reported during 48 hours of follow-up. Ramsook et al ${ }^{10}$ also looked at 48 hours of follow-up of emesis in a head-to-head comparison of ondansetron versus placebo. He found that the median number of episodes of vomiting remained 0 for the ondansetron group, with no statistically significant difference between groups. In contrast with this evidence, which would suggest little need to use ondansetron at home in order to reduce emesis between time of discharge and 24 hours, our study found that $24 \%$ of patients did have home emesis within 24 hours of being given a single dose in the emergency department. Our experience suggests that anticipation of an increase in diarrhea should be coupled with enhanced patient/parent education to decrease recurrent emergency department visits when ondansetron is used in this population.

\section{Conclusion}

This study demonstrates that home use of ondansetron via a discharge action plan (providing the medication prior to discharge) may be beneficial in reducing ongoing emesis, but more importantly increases medication compliance and at the same time does not cause adverse outcomes associated with the masking of alternative diagnoses. This series also emphasizes the importance of patient education regarding the side effect profile of ondansetron (related to diarrhea) in preventing recurrent emergency department visits. Larger prospective studies are warranted to support the above conclusions.

\section{Disclosure}

The authors have no financial or other conflicts of interest to disclose in relation to this work at the present time. 


\section{References}

1. King CK, Glass R, Bresee JS. Managing acute gastroenteritis among children: oral rehydration, maintenance, and nutritional therapy. $M M W R$ Recomm Rep. 2003;52:1-16.

2. Boschi-Pinto C, Velebit L, Shibuya K. Estimating child mortality due to diarrhoea in developing countries. Bull World Health Organ. 2008; 86(9):710-717.

3. American Academy of Pediatrics, Provisional Committee on Quality Improvement, Subcommittee on Acute Gastroenteritis. Practice parameter: the management of acute gastroenteritis in young children. Pediatrics. 1996;97:424-436.

4. Freedman SB, Adler M, Seshadri R, et al. Oral ondansetron for gastroenteritis in a pediatric emergency department. NEngl J Med. 2006; 20:1698-1705.

5. Sturm JJ, Hirsh DA, Schweickert A, Massey R, Simon HK. Ondansetron use in the pediatric emergency department and effects on hospitalization and return rates: are we masking alternative diagnoses? Ann Emerg Med. 2010;55:415-422.
6. Manteuffel J. Use of antiemetics in children with acute gastroenteritis: Are they safe and effective? J Emerg Trauma Shock. 2009;2:3-5.

7. Barkin RM, Ward DG. Infectious diarrheal disease and dehydration. In: Marx J, editor. Rosen's Emergency Medicine. 6th ed. St Louis, MO: Mosby Elsevier; 2006.

8. Kwon KT, Rudkin SE, Langdorf MI. Antiemetic use in pediatric gastroenteritis: A national survey of emergency physicians, pediatricians, and pediatric emergency physicians. Clin Pediatr (Phila). 2002;41: 641-652.

9. Li ST, DiGiuseppe DL, Christakis DA. Antiemetic use for acute gastroenteritis in children. Arch Pediatr Adolesc Med. 2003;157: 475-479.

10. Ramsook C, Sahagun-Carreon I, Kozinetz CA, Moro-Sutherland D. A randomized clinical trial comparing oral ondansetron with placebo in children with vomiting from acute gastroenteritis. Ann Emerg Med. 2002;39:397-403.

\section{Publish your work in this journal}

Open Access Emergency Medicine is an international, peer-reviewed, open access journal publishing original research, reports, editorials, reviews and commentaries on all aspects of emergency medicine. The manuscript management system is completely online and includes a very quick and fair peer-review system, which is all easy to use.
Visit http://www.dovepress.com/testimonials.php to read real quotes from published authors. 